\title{
Progressive Polytypism and Bandgap Tuning in Azetidinium Lead Halide Perovskites
}

Jiyu Tian ${ }^{1,2}$, David B. Cordes ${ }^{1}$, Alexandra M. Z. Slawin ${ }^{1}$, Eli Zysman-Colman²,* and Finlay D. Morrison $^{1, *}$

${ }^{1}$ EaStCHEM School of Chemistry, University of St Andrews, St Andrews, Fife, KY16 9ST, United Kingdom.

${ }^{2}$ Organic Semiconductor Centre, EaStCHEM School of Chemistry, University of St Andrews, St Andrews, Fife, KY16 9ST, United Kingdom.

\begin{abstract}
Mixed halide azetidinium lead perovskites $\mathrm{AzPbBr}_{3-x} \mathrm{X}_{x}(\mathrm{X}=\mathrm{Cl}$ or I) were obtained by mechanosynthesis. With varying halide composition from $\mathrm{Cl}^{-}$to $\mathrm{Br}^{-}$to $\mathrm{I}^{-}$; the chloride and bromide analogs both form in the hexagonal $6 \mathrm{H}$ polytype while the iodide adopts the $9 \mathrm{R}$ polytype. An intermediate $4 \mathrm{H}$ polytype is observed for mixed $\mathrm{Br} / \mathrm{I}$ compositions. Overall the structure progresses from $6 \mathrm{H}$ to $4 \mathrm{H}$ to $9 \mathrm{R}$ perovskite polytype with varying halide composition. Rietveld refinement of the powder X-ray diffraction patterns revealed a linear variation in unit cell volume as a function of the average radius of the anion, which is not only observed within the solid solution of each polytype (according to Vegard's law) but extends uniformly across all three polytypes. This is correlated with a progressive (linear) tuning of the bandgap from 3.41 to $2.00 \mathrm{eV}$. Regardless of halide, the family of azetidinium halide perovskite polytypes are highly stable, with no discernible change in properties over more than 6 months under ambient conditions.
\end{abstract}




\section{Introduction}

Hybrid organic inorganic halide perovskites have created much excitement as promising materials for solar cells, ${ }^{1-3}$ light-emitting diodes,${ }^{4,5}$ and photodetectors. ${ }^{6,7}$ These perovskite materials share a general formula $\mathrm{AMX}_{3}$, where the A-site cations occupy the interspace between $\mathrm{MX}_{6}$ octahedra ( $\mathrm{M}$ being a heavy group 16 element). The compositional variations among $\mathrm{A}, \mathrm{M}$ and $\mathrm{X}$ result in a diverse range of structures with distinct chemical, physical and optoelectronic properties, including band structure, ${ }^{8}$ primarily due to variations in $\mathrm{M}-\mathrm{X}$ bonding interactions and connectivity of octahedra. The most common polytype of these perovskites is the (pseudo-) cubic perovskite formed from a cubic (c-) close-packed stacking sequence of $\mathrm{AX}_{3}$ layers and, as a result, cornersharing $\mathrm{MX}_{6}$ octahedra. In Ramsdell notation ${ }^{9,10}$ perovskites formed from entirely cubic closepacked $\mathrm{AX}_{3}$ layers are indicated by the label $3 \mathrm{C}$, representing the three close packing layers of the aristotype cell and $\mathrm{C}$ for the cubic lattice type. For lead halide perovskites, such $3 \mathrm{C}$ polytypes are favored for tolerance factors, $t \leq 1$, which arise for relatively small A-site cations such as $\mathrm{Cs}^{+}$or methylammonium. For larger A-site cations, and $t>1$, hexagonal polytypes are obtained. ${ }^{11}$ These polytypes contain sequences of both cubic $(c-)$ and hexagonal $(h-)$ close-packed $\mathrm{AX}_{3}$ layers, or only hexagonal $(h-)$ packing. The resulting polytypes are also readily described using Ramsdell notation such as $2 \mathrm{H}(h h \ldots), 4 \mathrm{H}(h c h c \ldots), 6 \mathrm{H}(h c c h c c \ldots)$ etc, where, again, the numerical value describes the number of packing layers in the unit cell and $\mathrm{H}$ describes the lattice type, which is hexagonal in this instance (although rhombohedral variants such as $9 \mathrm{R}$ also exist). These sequences generate a number of possible combinations of corner-sharing and face-sharing octahedra. In general, the bandgap of perovskite materials can be tuned by modifying the ratio of corner-sharing to face-sharing ${ }^{12,13}$ octahedra as the nature of octahedral connectivity affects the $\mathrm{M}-\mathrm{X}$ orbital interactions that determine the energies of the valence and conduction bands.

Varying the halide composition is a common strategy for tuning the bandgap in hybrid halide perovskites. ${ }^{14-16}$ Yuiga et al. ${ }^{14}$ showed that the bandgap of $3 \mathrm{C}$ perovskite $\mathrm{MAPbBr}_{x} \mathrm{I}_{3-x}(\mathrm{MA}=$ methylammonium) varied quadratically from 1.65 to $2.38 \mathrm{eV}$ with increasing $\mathrm{Br}$ content accompanied by a symmetry change from tetragonal to cubic. Gratia et al. ${ }^{16}$ reported a crystallization process with a progressive structural change from $2 \mathrm{H}, 4 \mathrm{H}$ and $6 \mathrm{H}$ to $3 \mathrm{C}$ depending

on $x$ in $\left(\mathrm{FAPbI}_{3}\right)_{x}\left(\mathrm{MAPbBr}_{3}\right)_{1-x}(\mathrm{FA}=$ formamidinium $)$; however, DMSO solvent molecules were found to be present in the crystal lattice and it is unclear how their presence may affect the 
formation of the polytypes and their resulting band structure. Other benefits of mixed halide perovskites include improving solar cell power conversion efficiency ${ }^{17,18}$ and the stability of the perovskite materials. ${ }^{19,20}$ For example, Jeon et al. reported that incorporating $15 \% \mathrm{Br}$ in $\mathrm{FAPbI}_{3}$ lead to optimum power conversion efficiency of solar cells.${ }^{17}$ Furthermore, Jun et al. reported that mixing $15-20 \% \mathrm{Br}$ in $\mathrm{MAPbI}_{3}$ resulted in solar cells that could keep 95\% efficiency for more than 15 days after exposure to humidity, while the efficiency of $\mathrm{MAPbI}_{3}$ cells dropped below $50 \%$ after the exposure. ${ }^{19}$

One of the most commonly studied organic cations used at the A-site of this class of perovskites is methylammonium $\left(\mathrm{MA}^{+}\right)$. MA-containing perovskite materials are often used as a reference point for studies of the optoelectronic properties of hybrid perovskites. However, poor resistance to moisture remains an obstacle to the commercialization of MA-containing perovskites, especially for $\mathrm{MAPbI}_{3}$, which decomposes to $\mathrm{PbI}_{2}$ in the presence of water. ${ }^{21,22}$ Other cations have been investigated to address the poor stability, such as formamidinium, ${ }^{23,24} \mathrm{Cs}^{+},{ }^{25,26}$ azetidinium ${ }^{27}$ and guanidinium $^{28}$, amongst others.

Azetidinium $\left(\mathrm{Az}^{+}\right)$is a four-membered ring ammonium $\left(\mathrm{CH}_{2}\right)_{3} \mathrm{NH}_{3}{ }^{+}$, which is calculated to be a possible candidate for organic-inorganic hybrid perovskite with a tolerance factor ranging from 0.98 to 1.02 (from $\mathrm{AzPbI}_{3}$ to $\mathrm{AzPbCl}_{3}$ perovskite). The preparation of both $\mathrm{AzPbBr}_{3}{ }^{12}$ and $\mathrm{AzPbI}_{3}{ }^{29}$ from solution have been reported, where $6 \mathrm{H}$ and $9 \mathrm{R}$ perovskites were obtained, respectively. Our previous study on $\mathrm{Az}_{\mathrm{PbBr}}{ }_{3}^{12}$ showed that the material remains stable in ambient air for over 6 months. $\mathrm{AzPbI}_{3}$ crystals were able to partially maintain the $9 \mathrm{R}$ crystalline state after being submerged in distilled water for 50 days ${ }^{29}$ and an $\mathrm{AzPbI}_{3}$ thin film was reported to withstand exposure to moisture without decomposing ${ }^{27}$, although the exposure time was only for a few seconds.

In the current study, a family of azetidinium mixed halide perovskites, $\mathrm{AzPbBr}_{3-x} \mathrm{X}_{x}(\mathrm{X}=\mathrm{Cl}$ or I) were prepared by mechanosynthesis and their structures and optical absorption analyzed by both powder and single-crystal X-ray diffraction and absorption spectra, respectively. Besides the $6 \mathrm{H}$ polytype reported previously for $\mathrm{AzPbBr}_{3},{ }^{12}$ and $9 \mathrm{R}$ polytype reported for $\mathrm{AzPbI}_{3},{ }^{29}$ the chloride analogue is shown to also adopt the $6 \mathrm{H}$ structure and an intermediate hexagonal $4 \mathrm{H}$ polytype is identified for mixed Br-I compositions. Overall, the structure progresses from $6 \mathrm{H}$ to $4 \mathrm{H}$ to $9 \mathrm{R}$ perovskite polytypes with varying halide composition with varying degrees of solid solution 
formation within each structure type. The structural progression corresponds to a change in ratio of corner-sharing to face-sharing octahedra (Supporting Information, Table S1). Despite this variation in octahedral connectivity, the unit cell volume (normalized per formula unit) as a function of anion average radius varies linearly not only within each solid solution (in accordance with Vegard's law), but also across the entire polytype range. A tuneable bandgap is achieved ranging from 2.00 to $3.41 \mathrm{eV}$, which varies linearly as a function of average anion radius and the variation factor is similar to the reported factor of $\mathrm{APbBr}_{3-x} \mathrm{X}_{x}(\mathrm{~A}=\mathrm{MA}$, or $\mathrm{FA}, \mathrm{X}=\mathrm{Cl}$ or I $) .{ }^{30-32}$ The azetidinium halide perovskite polytypes remain highly stable for at least 6 months when stored in the ambient air.

\section{Experimental Methods}

\section{Synthesis}

$\mathrm{PbBr}_{2}(98 \%), \mathrm{PbI}_{2}(98 \%)$ and hydroiodic acid in water (57\%) were purchased from Alfa Aesar. Hydrobromic acid in water (48\%) and $\mathrm{AzCl}(95 \%)$ were purchased from Fluorochem. All other reagents and solvents were obtained from commercial sources and used as received.

For preparation of azetidinium iodide (AzI), potassium hydroxide (1.30 g, 23 mmol, 1.5 equiv.) was dissolved in $3 \mathrm{~mL}$ DI water and mixed with azetidinium chloride (1.45 g, 15 mmol, 1 equiv.) under stirring for $30 \mathrm{~min}$. The intermediate azetidine was extracted at $80{ }^{\circ} \mathrm{C}$ under reduced pressure and condensed with liquid nitrogen. Hydroiodic acid ( $3 \mathrm{~mL}, 23 \mathrm{mmol}, 1.5$ equiv.) was then added into the condensed azetidine solution and stirred for $30 \mathrm{~min}$ at room temperature. The solvent was then removed under reduced pressure at $80^{\circ} \mathrm{C}$. The crude products were dissolved in $3 \mathrm{~mL} \mathrm{EtOH}$ and the product recrystallized from diethyl ether. The recovered solid was dried under vacuum for $24 \mathrm{~h}$ before use. White needle-like crystals were obtained. The NMR of AzI is shown in Figure S1. Yield: $86 \%$. Mp.:137-138 ${ }^{\circ} \mathrm{C}{ }^{1} \mathrm{H}$ NMR (500 MHz, DMSO- $\left.d_{6}\right) \delta$ (ppm) 8.42 (s, 2H), $3.98-$ 3.89 (m, 4H), 2.37 (p, $J=8.3 \mathrm{~Hz}, 2 \mathrm{H}) .{ }^{13} \mathrm{C}$ NMR (126 MHz, DMSO-d $) \delta$ (ppm) 46.53, 18.93. Elemental Analysis. Calculated for $\mathrm{C}_{3} \mathrm{H}_{8} \mathrm{NI}$ : C, 19.48; H, 4.36; N, 7.57; I, 68.59; Found: C, 19.61; H, 4.24; N, 7.66.

$\mathrm{AzPbCl}_{3}$ samples were prepared by dissolving $\mathrm{AzCl}$ and $\mathrm{PbCl}_{2}(1: 1)$ in $\mathrm{DMSO}(2 \mathrm{~mL}, 0.4 \mathrm{M})$ at room temperature and in air. After stirring for $1 \mathrm{~h}$ clear solutions were obtained. DCM $(8 \mathrm{~mL})$ was added slowly into the solution and the vial was shaken for $1 \mathrm{~min}$ and then left to stand for $10 \mathrm{~min}$ 
before vacuum filtration. The resulting powders were washed with $10 \mathrm{~mL}$ DCM twice and dried under vacuum for $24 \mathrm{~h}$. The samples were white powders. Single crystals of $\mathrm{AzPbCl}_{3}$ were obtained by slow diffusion of antisolvent DCM into the same concentration perovskite/DMSO solution in a sealed vial. White needle-like crystals were obtained.

Preparation of both $\mathrm{AzPbCl}_{x} \mathrm{Br}_{3-x}$ and $\mathrm{AzPbI}_{x} \mathrm{Br}_{3-x}$ solid solutions with $0 \leq x \leq 3$ was carried out by mechanosynthesis. Appropriate molar ratios of $\mathrm{Az} /$ halide source $\left(\mathrm{AzPbCl}_{3}, \mathrm{AzBr}\right.$ or $\left.\mathrm{AzI}\right)$ and lead/halide source $\left(\mathrm{PbCl}_{2}, \mathrm{PbBr}_{2}\right.$ or $\left.\mathrm{PbI}_{2}\right)$ were ground together in a Fritsch Pulverisette planetary ball mill at $600 \mathrm{rpm}$ for 1 hour using $60 \mathrm{~cm}^{3}$ Teflon pots and high-wear-resistant zirconia media (nine zirconia grinding media $10 \mathrm{~mm}$ diameter spheres).

Single crystals of $\mathrm{AzPbCl}_{3}, \mathrm{AzPbBr}_{1.5} \mathrm{I}_{1.5}$ and $\mathrm{AzPbI}_{3}$ for comparison with mechanosynthesized samples were prepared by slow diffusion of antisolvent DCM/acetonitrile/acetonitrile into DMSO, DMF/DSMO (4:1) and DMF/ $\gamma$-butyrolactone (1:1) solution, respectively. $\mathrm{AzPbCl}_{3}$ appears as white needle-like crystals while $\mathrm{AzPbBr}_{1.5} \mathrm{I}_{1.5}$ and $\mathrm{AzPbI}_{3}$ crystals are bright yellow and dark red, respectively. During crystallization of $\mathrm{AzPbBr}_{1.5} \mathrm{I}_{1.5}$, there was evidence of formation of crystals of other compounds; in one case indexing of the data suggested the presence of $\mathrm{AzPbI}_{3}$. This suggests that the mixed halide is not favored against the single-halide forms of the complex during recrystallization and vice versa. Given some of the data-issues encountered (vide infra), it is possible that the selected crystals of $\mathrm{AzPbBr}_{1.5} \mathrm{I}_{1.5}$ may have contained domains or crystallites of $\mathrm{AzPbBr}_{3}$ or $\mathrm{AzPbI}_{3}$.

Single crystal samples prepared by precipitation synthesis and powder samples prepared by either precipitation or mechanosynthesis routes were characterized by single crystal and powder X-ray diffraction (SCXRD and PXRD, respectively). SCXRD data were collected at either at 293, 173, or $93 \mathrm{~K}$ using a Rigaku FR-X Ultrahigh Brilliance Microfocus RA generator/confocal optics with XtaLAB P200 diffractometer [Mo K $\alpha$ radiation $(\lambda=0.71075 \AA)$ ]. Intensity data were collected using $\omega$-steps accumulating area detector images spanning at least a hemisphere of reciprocal space. Details of structure solution and refinement are provided in the Supporting Information. PXRD was carried out either using a PANalytical Empyrean diffractometer with $\mathrm{Cu} \mathrm{K}_{\alpha 1}(\lambda=$ $1.5406 \AA$ ). Rietveld refinements of PXRD data using GSAS $^{33}$ were used to confirm phase formation and for determination of lattice parameters. 
Optical properties were determined from solid-state absorption spectra recorded using a JASCOV650 double beam spectrophotometer and bandgaps were calculated using the 'Band-Gap Calculation' program of the spectrophotometer which applies the Tauc method.

Sample morphologies were investigated using a Jeol JSM-5600 Scanning Electron Microscope with an accelerating voltage set at $5 \mathrm{kV}$.

${ }^{1} \mathrm{H}$ and ${ }^{13} \mathrm{C}$ Nuclear magnetic resonance (NMR) spectra were recorded on a Bruker Advance spectrometer $\left(500 \mathrm{MHz}\right.$ for ${ }^{1} \mathrm{H}, 126 \mathrm{MHz}$ for ${ }^{13} \mathrm{C}$ ). ${ }^{1} \mathrm{H}$ and ${ }^{13} \mathrm{C}$ NMR spectra were referenced to residual solvent peaks with respect to $\operatorname{TMS}(\delta=0 \mathrm{ppm})$.

\section{Results and Discussion}

Commercially available $\mathrm{AzCl}$ was found to be too impure ( $<90 \%$, discussed in Supporting Information and shown in Figure S2) to use in the mechanosynthesis, so $\mathrm{AzPbCl}_{3}$ prepared by precipitation synthesis, with purity confirmed by powder X-ray diffraction (PXRD), was used as the $\mathrm{Az} / \mathrm{Cl}$ source. Attempts to prepare $\mathrm{AzPbCl}_{3}$ by mechanosynthesis using commercial $\mathrm{AzCl}$ required a stoichiometric excess of $\mathrm{AzCl}$ to converge to the desired product. While PXRD showed successful preparation of single-phase $\mathrm{AzPbCl}_{3}$ using this excess (Figure $\mathbf{S 3}$ ), the presence of small amounts of $\mathrm{AzCl}$, which may not be detectable by PXRD, cannot be excluded. Thus, the following analysis of $\mathrm{AzPbCl}_{3}$ was based only on precipitation-synthesized samples.

The color progression (Figure 1a) of the as-synthesized $\mathrm{AzPbCl}_{x} \mathrm{Br}_{3-x}$ is subtle and ranges from white $\left(\mathrm{AzPbCl}_{3}\right)$ to pale yellow $\left(\mathrm{AzPbBr}_{3}\right)$; the colors of the $\mathrm{AzPbBr}_{x} \mathrm{I}_{3-x}$ series, by contrast, show a clear and systematic change from pale yellow $\left(\mathrm{AzPbBr}_{3}\right)$ to red orange $\left(\mathrm{AzPbI}_{3}\right)$. The PXRD of the mixed halide perovskites are shown in Figures $\mathbf{1 b}$ and 1c. The PXRD of $\mathrm{AzPbCl}_{3}$ shows the same $6 \mathrm{H}$ hexagonal structure as $\mathrm{AzPbBr}_{3},{ }^{12}$ Single crystal X-ray diffraction (SCXRD) at ambient temperature and $173 \mathrm{~K}$ confirms the $6 \mathrm{H}$ polytype (Figure 2 ) with space group $P 6_{3} / m m c$ [PXRD: $a$ $=8.515(6) \AA, c=20.44(9) ; \operatorname{SCRXD}(293 \mathrm{~K}): a=8.5166(2) \AA, c=20.4424(6) \AA ; \operatorname{SCRXD}(173$ $\mathrm{K}): a=8.4763(2) \AA, c=20.3303(6) \AA]$. The PXRDs of the Br-rich region for $\mathrm{AzPbBr}_{3-x} \mathrm{Cl}_{x} \mathrm{Samples}$ show additional broad features in the base of the main peaks and which are especially evident around $12-14^{\circ}$. These features match well with the reported features from bimodal CdS particles ${ }^{34}$ and indicate the presence of multiple subpopulations of different sizes of $6 \mathrm{H}$ perovskite particles. 
In our previous study, the PXRD of precipitation-synthesized $\mathrm{AzPbBr}_{3}$ did not show such features. ${ }^{12}$ Scanning electron microscopy (SEM) of both mechano- and precipitation synthesized $\mathrm{AzPbBr}_{3}$ (Figure $\mathbf{S 4}$ ) indicate the presence of a large proportion of relatively smaller particles in the mechanosynthesized $\mathrm{AzPBBr}_{3}$, explaining the broad base of the PXRD peaks in Figure 1b.

a)

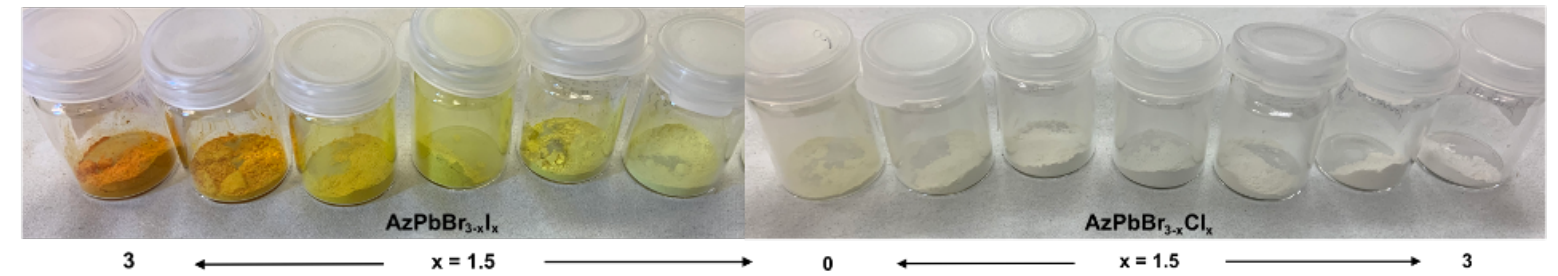

b)

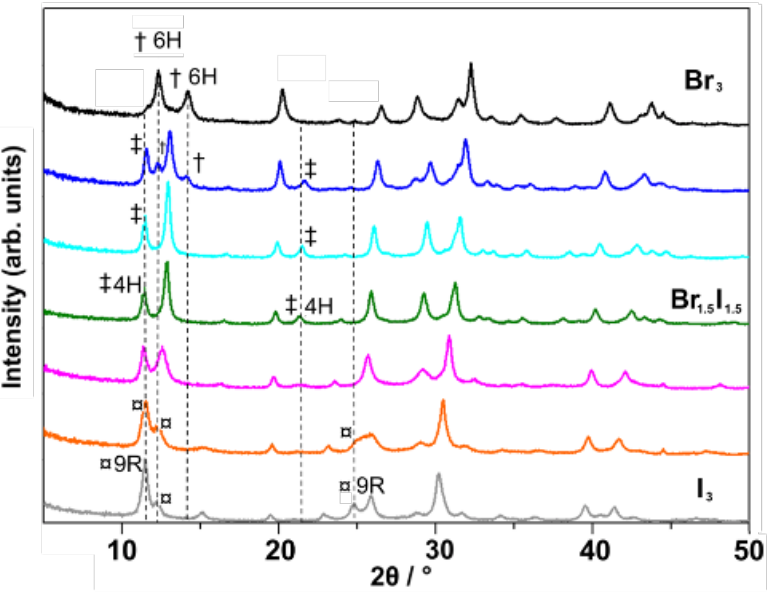

c)

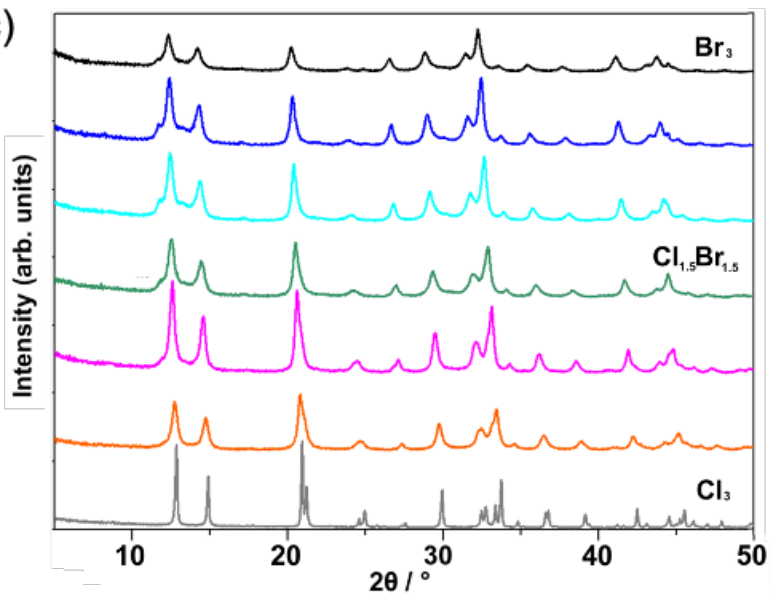

Figure 1. (a) Photos and (b, c) PXRD patterns of mixed halide perovskite: $\mathrm{AzPbBr}_{3-x} \mathrm{X}_{x}(\mathrm{X}=\mathrm{Cl}$ or I) with composition $0 \leqslant x \leqslant 3$ (in $x=0.5$ increments) prepared by mechanosynthesis, except $\mathrm{AzPbCl}_{3}$ which was prepared by precipitation synthesis. $\ddagger 6 \mathrm{H}, \uparrow 4 \mathrm{H}$, $\mathrm{a} 9 \mathrm{R}$ indicate selected peaks for each corresponding polytype.

$\mathrm{AzPbI}_{3}$ has been reported previously as a $9 \mathrm{R}$ polytype ${ }^{29}$ and the Rietveld refinement (Figure S5) of the PXRD confirms that the $9 \mathrm{R} \mathrm{AzPbI}_{3}$ perovskite can also be obtained easily by mechanosynthesis compared with the reported two-step recrystallisation method in solution. ${ }^{29}$ This is also confirmed by the SCXRD structure, although, as has been the case in previous attempts to determine the structure of $\mathrm{AzPbI}_{3}$ by $\mathrm{SCXRD},{ }^{29}$ the apparent crystal quality prevented the confirmation of the $\mathrm{Az}^{+}$cation sites. This was observed for data collected at both ambient temperature and $173 \mathrm{~K}$. In the case of this structure, both resulted in a lattice parameter, $a$, smaller than that determined by Rietveld refinement, the ambient temperature structure being closer to that 
seen in the refined PXRD data, however, both SCXRD structures had a $c$ lattice parameter larger than that determined by Rietveld refinement [SCXRD (293 K): $a=9.0835(5) \AA, c=35.104(3) \AA$; $\operatorname{SCRXD}(173 \mathrm{~K}): a=8.983(2) \AA, c=35.130(10) \AA$; PXRD $a=9.101(1) \AA, c=35.00(2) \AA]$. The PXRD data of $\mathrm{AzPbBr}_{x} \mathrm{I}_{3-x}(x \leq 2)$ seem to indicate a structure that was neither 6H, 9R nor a twophase mixture of these two polytypes; however, the hypothesis was that $\mathrm{AzPbBr}_{x} \mathrm{I}_{3-x}(x \leq 2)$ is still some form of perovskite (or a mixture of perovskite polytypes). Analysis of the PXRD of $\mathrm{Az} \mathrm{PbBr}_{1.5} \mathrm{I}_{1.5}$, in particular, the $d$-spacing of the two major peaks at $11.41^{\circ}$ and $12.86^{\circ}$, reveals the intermediate structure to be the $4 \mathrm{H}$ polytype with $P 6_{3} / m m c$ space group (Figure 2). The $4 \mathrm{H}$ perovskite structure has an $(h c)_{2}$ stacking sequence in Jagodzinski notation, resulting in alternating face-sharing and corner-sharing octahedra. The goodness-of-fit parameters from the Rietveld refinement of $\mathrm{AzPbBr} \mathrm{Pb}_{1.5} \mathrm{I}_{1.5}$ to an adapted 4H model (Figure S6) indicate a good fit: $\chi^{2}=3.509$, $w R_{p}=7.5 \%$. SCXRD of the $\mathrm{Az} \mathrm{PbBr}_{1.5} \mathrm{I}_{1.5}$ suggested that in single crystals prepared by precipitation a mixture of phases exist, potentially including the $\mathrm{AzPbX}_{3}$ single-halide materials; no evidence of mixed phase was evident in the same compositions prepared by mechanosynthesis, again highlighting the need for caution for samples prepared using the kinetically-controlled precipitation route compared to thermodynamically-controlled mechanosynthesis. ${ }^{35}$ However, it did prove possible to isolate and structurally characterize $\mathrm{AzPbBr}_{1.5} \mathrm{I}_{1.5}$ by SCXRD. As was the case with the iodide compound, crystal quality precluded modelling of the $\mathrm{Az}^{+}$sites, both for ambient temperature data, and for that collected at $173 \mathrm{~K}$. Both structures showed lattice parameters smaller than that determined by Rietveld refinement (Table S2), the ambient temperature structure being closer to that seen in the refined PXRD data [SCXRD (293 K): $a=$ 8.958(4) $\AA, c=14.846(6) \AA ; \operatorname{SCXRD~(93~K):~} a=8.851(5) \AA, c=14.760(8) \AA ̊$; PXRD (ambient): $a=8.964(3) \AA, c=14.82(9) \AA]$. The perovskite samples were re-examined by PXRD after being stored in ambient air for 6 months and no visual or structural decomposition was observed (Figure S7). 


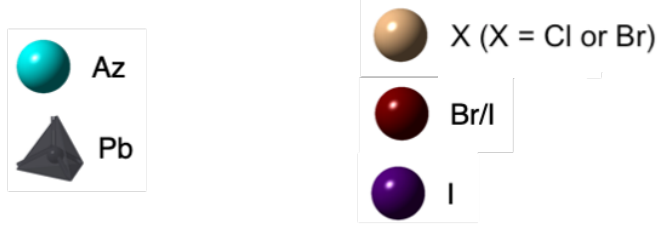

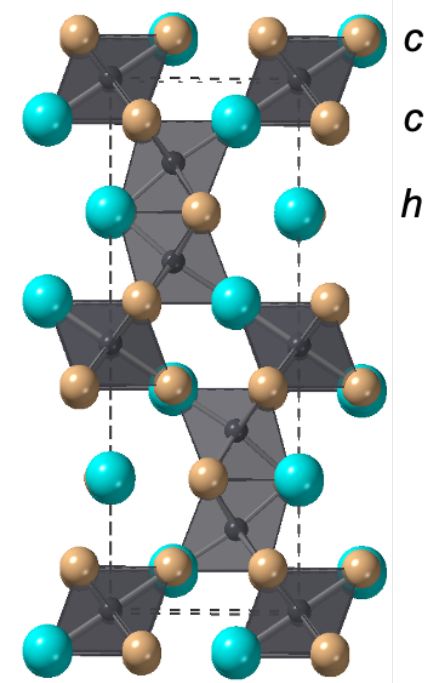

$6 \mathrm{H}$

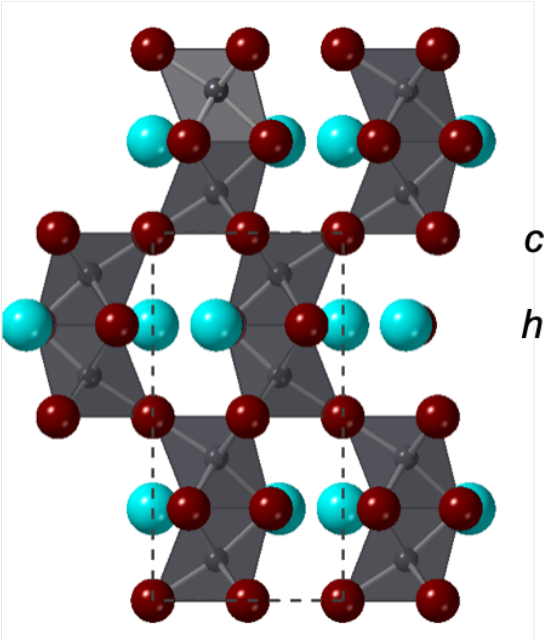

$4 \mathrm{H}$

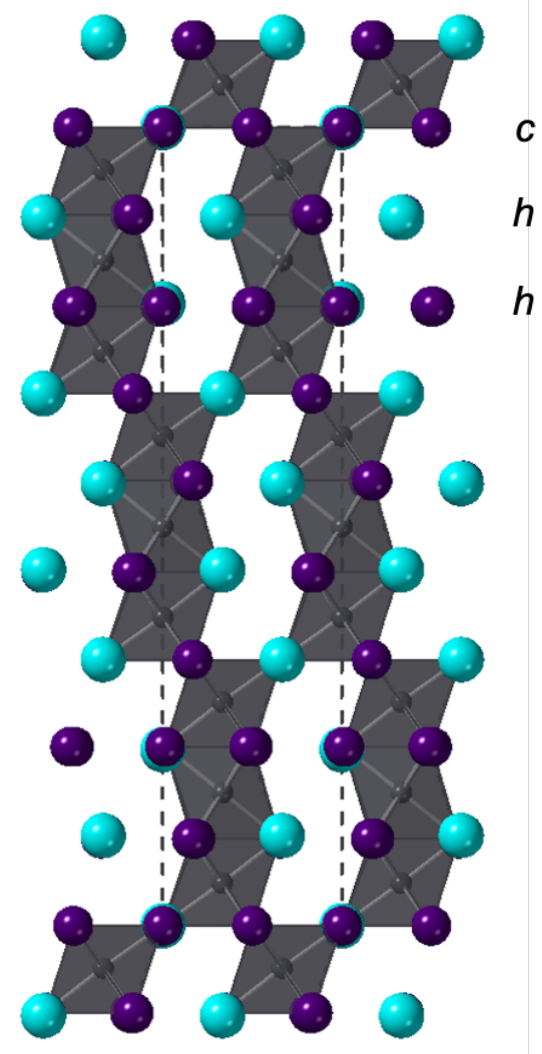

9R

Figure 2. Structures determined from (both powder and single crystal) XRD data of different azetidinium lead halide perovskite polytypes: $6 \mathrm{H}\left(\mathrm{AzPbX}_{3}, \mathrm{X}=\mathrm{Br}, \mathrm{Cl}\right), 4 \mathrm{H}\left(\mathrm{AzPbBr}_{1.5} \mathrm{I}_{1.5}\right)$ and 9R $\left(\mathrm{AzPbI}_{3}\right)$ viewed along $\boldsymbol{a}$, where the $\mathrm{AX}_{3}$ stacking sequence is denoted with $h$ - and $c$ - for hexagonal and cubic close packed layers, respectively.

To study the solid solutions within, and transition between, these polytypes, the lattice parameters of each mechanosynthesized composition were determined by Rietveld refinement of PXRD data. The lattice parameters of the single halide perovskites $\mathrm{AzPbX}_{3}(\mathrm{X}=\mathrm{Cl}, \mathrm{Br}, \mathrm{I})$ and also $4 \mathrm{H}$ $\mathrm{AzPbBr}_{1.5} \mathrm{I}_{1.5}$ are shown in Table 1. The average interlayer distance along the $c$-axis $(\bar{c})$ and lattice parameter $a$ increase with the transition sequence from $6 \mathrm{H}$ to $4 \mathrm{H}$ to $9 \mathrm{R}$. The cell volume (normalized to the number of formula units per unit cell) of those polytypes varies linearly as a function of average anion radius, Figure 3a (the average anion radius was calculated using $r_{\mathrm{I}}=220$ $\mathrm{pm}, r_{\mathrm{Br}}=196 \mathrm{pm}$ and $r_{\mathrm{Cl}}=181 \mathrm{pm}$ according to Shannon ${ }^{36}$ ). While this linear variation within 
each polytype solid solution is expected in accordance with Vegard's law, it is interesting to note that the linear relationship extends continuously across all three polytypes. Presumably this reflects the $\mathrm{AX}_{3}$ close packing volume; however, it suggests that the polytype adopted is largely driven by the degree of $\mathrm{Pb}-\mathrm{Pb}$ interactions, which is emphasized in face-sharing $(h)$ layers. The substitution of increasingly large, and less electronegative, halide anions result in an expansion of $\mathrm{MX}_{6}$ octahedra, which decreases the electrostatic energy (Madelung energy) of the ionic crystals and allows for more face sharing octahedral layers and $\mathrm{Pb}-\mathrm{Pb}$ proximity.

Table 1. Lattice parameters and goodness-of-fit parameters for Rietveld refinement of PXRD data for single and mixed halide perovskite compositions.

\begin{tabular}{c|cccc}
\hline & $\mathrm{AzPbCl}_{3}$ & $\mathrm{AzPbBr}_{3}$ & $\mathrm{AzPbBr}_{1.5} \mathrm{I}_{1.5}$ & $\mathrm{AzPbI}_{3}$ \\
\hline Space group & $P 6_{3} / m m c$ & $P 6_{3} / m m c$ & $P 6_{3} / m m c$ & $R \overline{3}$ \\
Polytype & $6 \mathrm{H}$ & $6 \mathrm{H}$ & $4 \mathrm{H}$ & $9 \mathrm{R}$ \\
$a / \AA$ & $8.515(6)$ & $8.758(2)$ & $8.964(3)$ & $9.101(1)$ \\
$c / \AA$ & $20.44(9)$ & $21.42(5)$ & $14.82(9)$ & $35.00(2)$ \\
volume / $\AA^{3}$ & $1284.2(6)$ & $1423.3(0)$ & $1032.0(4)$ & $2510.8(3)$ \\
$\bar{c} / \AA *$ & 3.408 & 3.570 & 3.707 & 3.889 \\
$\chi^{2}$ & 3.066 & 4.697 & 3.509 & 1.545 \\
$w R_{p}$ & 0.069 & 0.083 & 0.075 & 0.056 \\
\hline
\end{tabular}

* The average interlayer distance along $c$-axis.

In addition to the $4 \mathrm{H}, 6 \mathrm{H}$ and $9 \mathrm{R}$ single phase solid solutions, intermediate two-phase regions of $6 \mathrm{H}-4 \mathrm{H}$ and $4 \mathrm{H}-9 \mathrm{R}$ were also identified by PXRD, as shown in Figure 3a. For the 6H-4H two phase-region, the peaks of both phases could be readily identified, but the boundary of the $4 \mathrm{H}-9 \mathrm{R}$ two-phase region was difficult to ascertain due to the overlap of the major peaks (Figure 1b). Attempts at two-phase refinement of PXRD data of both two-phase regions were unsuccessful due to the overall breadth of peaks, overlap of major peaks and relatively low intensities of non- 
overlapping peaks. As a result, no lattice parameters are provided for the $6 \mathrm{H}-4 \mathrm{H}$ two-phase region. For the 4H-9R two-phase region, the data for compositions $\mathrm{AzPbBrI}_{2}$ and $\mathrm{AzPbBr}_{0.6} \mathrm{I}_{2.4}$ which appear close to the phase boundaries were refined as single-phase $4 \mathrm{H}$ and $9 \mathrm{R}$, respectively, as approximations, and the resulting lattice parameters matched quite well with the linear fit as a function of average anion radius. As a general comparison, the cell volumes as a function of average anion radius for $3 \mathrm{C} \mathrm{FAPbX}$ and $\mathrm{MAPbX}_{3}$ mixed halide perovskites ${ }^{30-32}$ are shown in Figure S8a and display similar linear behavior, but this unlike the $\mathrm{AzPbX}_{3}$ compositions of the current study all MA- and FA-compositions adopt a single (3C) polytype.

a)

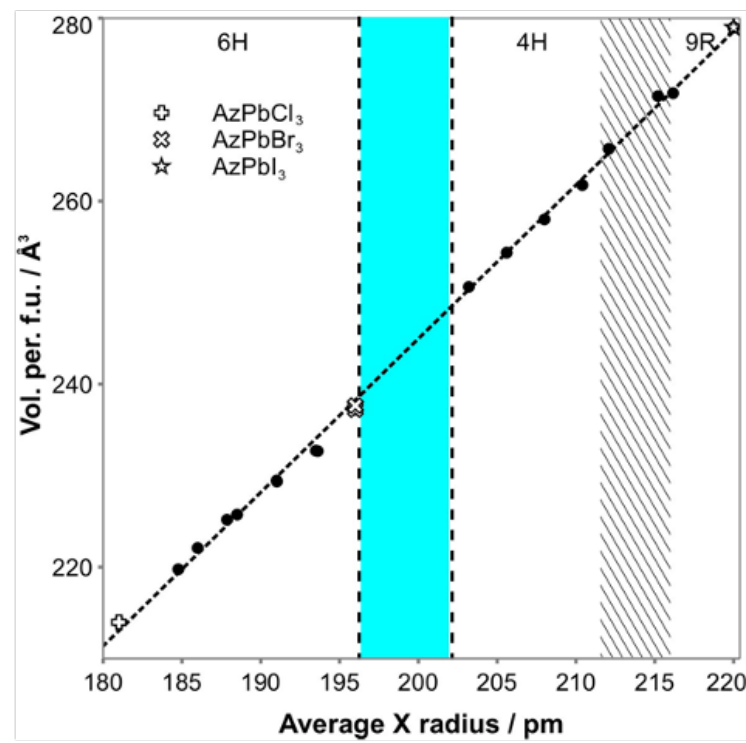

b)

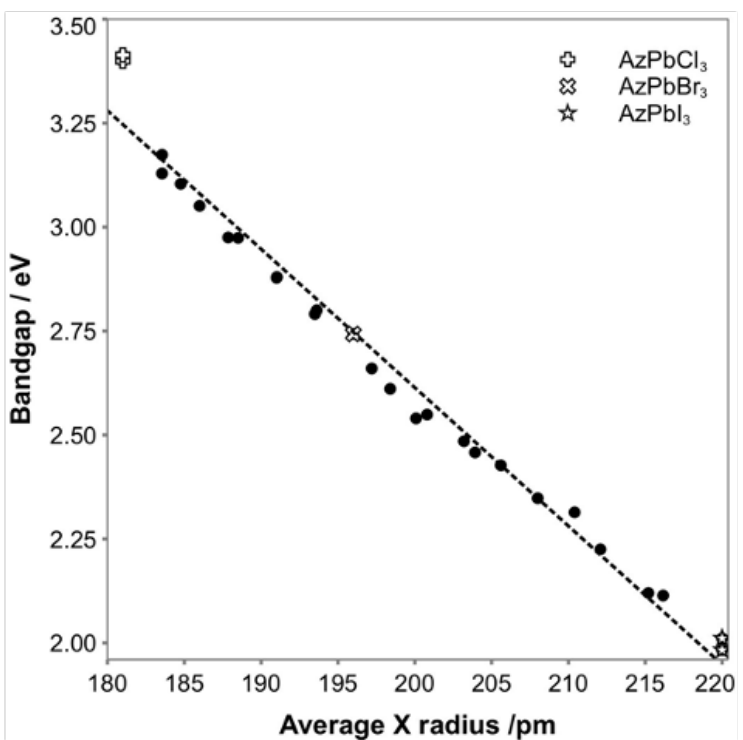

Figure 3. a) Cell volume (per formula unit) of mixed halide perovskite determined by Rietveld refinement of PXRD data and b) the bandgap determined from absorption spectra of samples $\mathrm{AzPbBr}_{3-x} \mathrm{X}_{x}(\mathrm{X}=\mathrm{Cl}$ or I) with composition $0 \leq x \leq 3$ plotted as a function of average halide anion radius. Intermediate $6 \mathrm{H}-4 \mathrm{H}$ (shaded) and $4 \mathrm{H}-9 \mathrm{R}$ (hatched) two phase-regions are indicated.

The optical properties of the different phases were studied by absorption spectroscopy (Figure 4). The absorption onsets are systematically red-shifted with increasing average anion size (from $\mathrm{Cl}$ to I). The absorption onset of $\mathrm{AzPbBr}_{3-x} \mathrm{X} x(\mathrm{X}=\mathrm{Cl}$ or I, $0 \leqslant x \leqslant 3)$ samples show a red shift from ca. $360 \mathrm{~nm}\left(3.44 \mathrm{eV}, \mathrm{AzPbCl}_{3}\right)$, to ca. $450 \mathrm{~nm}\left(2.76 \mathrm{eV}, \mathrm{AzPbBr}_{3}\right)$, to ca. $615 \mathrm{~nm}\left(2.02 \mathrm{eV}, \mathrm{AzPbI}_{3}\right)$. The background absorption of intermediate compositions in $\mathrm{AzPbCl}_{x} \mathrm{Br}_{3-x}$ samples lies above the 
normalized zero baseline, especially for $x=2.5$. This might result from a small number of Br-rich crystallites on the sample surface, the amount of which is too small to be detected in PXRD. The absorption of $\mathrm{AzPbI}_{3}$ bore close resemblance to the reported spectrum, ${ }^{29}$ where three well-defined transitions could be detected; the peak maxima of the three well-defined transitions are at 551, 506, $470 \mathrm{~nm}$ while the reported transitions peak at 554, 503, $462 \mathrm{~nm}$.

a)

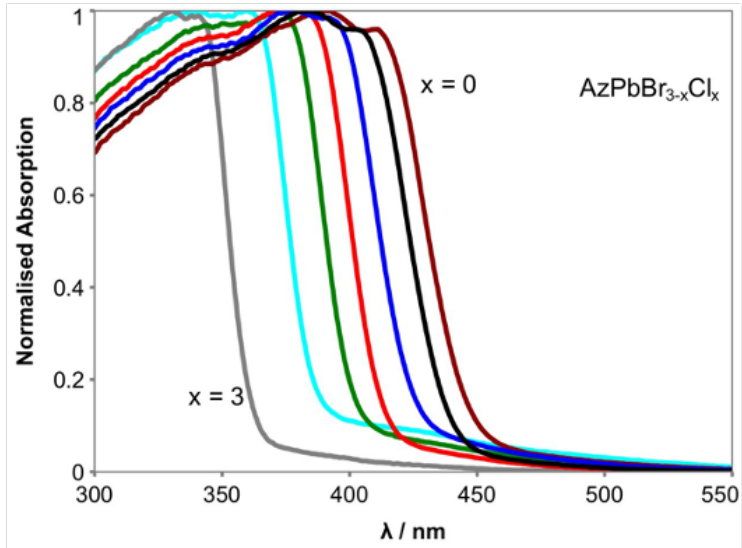

b)

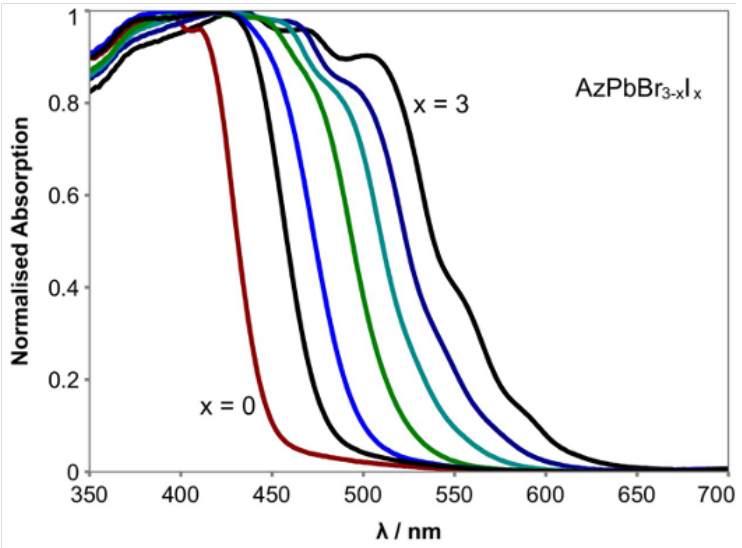

Figure 4. Absorption spectra of a) $\mathrm{AzPbBr}_{3-x} \mathrm{Cl}_{x}$ b) $\mathrm{AzPbBr}_{3-x} \mathrm{I}_{x}(0 \leq x \leq 3$, in $x=0.5$ increments $)$; all samples were prepared by mechanosynthesis.

The bandgap as a function of halide composition for the mixed halide perovskites is shown in Figure 3b. The bandgap of $\mathrm{AzPbCl}_{3}$ and $\mathrm{AzPbI}_{3}$ were calculated to be $3.41 \pm 0.01 \mathrm{eV}$ and $2.00 \pm$ $0.02 \mathrm{eV}$, respectively. The latter is in good agreement with the previously reported value of 1.97 $\mathrm{eV} .{ }^{29}$ The bandgap varies linearly as a function of average anion radius, despite the change of halide composition and octahedral connectivity. As discussed in our previous study, the varying ratio of corner-sharing to face-sharing octahedral connectivity changes the efficiency of $\mathrm{Pb}-\mathrm{X}$ orbital overlap; in conjunction with the change in $\mathrm{Pb}-\mathrm{X}$ bond length, average bond angles and covalency which give rise to the bandgap variation. ${ }^{12}$ Comparison of the behavior of the Az-based perovskites with corresponding MA-, and FA-based mixed halide perovskites shows that the lattice parameter progression as a function of halide composition is linear in all cases; however, the reported relation of bandgap versus halide composition is not consistent across these studies. Some studies reported a nonlinear relation, which is described as a bowing effect, ${ }^{19,30,37}$ while other studies document a linear progression ${ }^{38,39}$ as observed here. Bandgap "bowing" is often fitted to a second order polynomial, with a bowing parameter $b$ as the binominal coefficient of the fitting 
equation. The bowing parameters of $\mathrm{MAPbBr}_{3-x} \mathrm{X}_{x}\left(\mathrm{X}=\mathrm{Cl}\right.$ or I) are relatively small $\left(7 \times 10^{-4}\right.$ to $0.33)^{19,30}$ compared to the bowing parameters ( 0.5 to 1.33 ) found for other mixed metal perovskite systems. ${ }^{40-43}$ Our study illustrates a good example of a linear variation between bandgap and halide composition, and it is as of yet unclear why both linear and non-linear relationship were reported for other mixed halide perovskites with same organic cation and metal. However, this may related to anion segregation when prepared using kinetically-controlled precipitation routes. ${ }^{35,44}$

\section{Summary and Conclusions}

Following on from studies on azetidinium lead bromide, mixed halide compositions, $\mathrm{AzPbBr}_{3-x} \mathrm{X}_{x}$ $(\mathrm{X}=\mathrm{Cl}$ or $\mathrm{I}$ ), were successfully synthesized using a mechanosynthetic grinding method. The single-phase single halide materials $\mathrm{AzPbX}_{3}(\mathrm{X}=\mathrm{Cl}, \mathrm{Br}$ or I) were shown to be stable in air for $>$ six months. In addition to the $6 \mathrm{H}$ polytype reported previously for $\mathrm{Az} \mathrm{PbBr}_{3},{ }^{12}$ and $9 \mathrm{R}$ polytype reported for $\mathrm{AzPbI}_{3},{ }^{29} \mathrm{AzPbCl}_{3}$ was also shown to form in the $6 \mathrm{H}$ polytype and an additional $4 \mathrm{H}$ polytype was found for $\mathrm{AzPbBr}_{3-x} \mathrm{I}_{x}(c a .0<x \leqslant 2)$ compositions. With varying halide composition, the structure progresses from $6 \mathrm{H}$ to $4 \mathrm{H}$ to $9 \mathrm{R}$ perovskite polytype. A complete (continuous) solid solution is formed for compositions with the $6 \mathrm{H}$ structure and partial solid solutions form between the $6 \mathrm{H}$ and $4 \mathrm{H}$ and $4 \mathrm{H}$ and $9 \mathrm{R}$ polytypes. A linear variation in unit cell volume (scaled per formula unit) as a function of anion average radius is observed not only within the solid solution of each polytype (according to Vegard's law) but continuously across all three polytypes, which, to the best of our knowledge, is the first time that Vegard's law-type behavior has been observed across several polytypes. This linear relationship extending across all compositions is accompanied by a linearly tuneable bandgap ranging from 2.00 to $3.41 \mathrm{eV}$ as a function of average anion radius without any observations of a "bowing effect". The linear variation of bandgap across all $\mathrm{AzPbX}$ compositions (and polytypes) is comparable to that observed in $\mathrm{APbBr}_{3-x} \mathrm{X}_{x}(\mathrm{~A}=\mathrm{MA}$, or $\mathrm{FA}, \mathrm{X}=$ $\mathrm{Cl}$ or I) but that all adopt a single (3C) polytype. ${ }^{30-32}$

Associated content

\section{Supporting Information}


The Supporting Information contains additional experimental information including: details of ${ }^{1} \mathrm{H}$ NMR analysis, PXRD analysis, SXRD analysis, SEM, examples of Rietveld refinement, absorption spectra and bandgap analysis. The research data supporting this publication can be accessed at [].

Author information

Corresponding authors:

eli.zysman-colman@st-andrews.ac.uk

finlay.morrison@st-andrews.ac.uk

Acknowledgements

We thank the Chinese Scholarship Council for Ph.D. Studentship support (to JT, CSC No. 201603780020).

\section{References}

(1) Hou, Y.; Aydin, E.; De Bastiani, M.; Xiao, C.; Isikgor, F. H.; Xue, D.-J.; Chen, B.; Chen, H.; Bahrami, B.; Chowdhury, A. H.; et al. Efficient Tandem Solar Cells with SolutionProcessed Perovskite on Textured Crystalline Silicon. Science (80-. ). 2020, 367 (6482), $1135-1140$.

(2) Alsalloum, A. Y.; Turedi, B.; Zheng, X.; Mitra, S.; Zhumekenov, A. A.; Lee, K. J.; Maity, P.; Gereige, I.; AlSaggaf, A.; Roqan, I. S.; et al. Low-Temperature Crystallization Enables 21.9\% Efficient Single-Crystal MAPbI 3 Inverted Perovskite Solar Cells. ACS Energy Lett. 2020, 5 (2), 657-662.

(3) Liu, J.; Han, Q.; Bai, Y.; Du, K. Z.; Li, T.; Ji, D.; Zhou, Y.; Cao, C.; Shin, D.; Ding, J.; et al. Additive Engineering for High-Performance Room-Temperature-Processed Perovskite Absorbers with Micron-Size Grains and Microsecond-Range Carrier Lifetimes. Energy Environ. Sci. 2017, 10 (11), 2365-2371. 
(4) Liang, H.; Yuan, F.; Johnston, A.; Gao, C.; Choubisa, H.; Gao, Y.; Wang, Y.; Sagar, L. K.; Sun, B.; Li, P.; et al. High Color Purity Lead-Free Perovskite Light-Emitting Diodes via Sn Stabilization. Adv. Sci. 2020, 7 (8), 1903213.

(5) Ma, D.; Todorović, P.; Meshkat, S.; Saidaminov, M. I.; Wang, Y.-K.; Chen, B.; Li, P.; Scheffel, B.; Quintero-Bermudez, R.; Fan, J. Z.; et al. Chloride Insertion-Immobilization Enables Bright, Narrowband, and Stable Blue-Emitting Perovskite Diodes. J. Am. Chem. Soc. 2020, 142 (11), 5126-5134.

(6) Cao, M.; Tian, J.; Cai, Z.; Peng, L.; Yang, L.; Wei, D. Perovskite Heterojunction Based on CH3NH3PbBr3 Single Crystal for High-Sensitive Self-Powered Photodetector. Appl. Phys. Lett. 2016, 109 (23), 233303.

(7) Zhou, H.; Song, Z.; Grice, C. R.; Chen, C.; Yang, X.; Wang, H.; Yan, Y. Pressure-Assisted Annealing Strategy for High-Performance Self-Powered All-Inorganic Perovskite Microcrystal Photodetectors. J. Phys. Chem. Lett. 2018, 9 (16), 4714-4719.

(8) Stoumpos, C. C.; Malliakas, C. D.; Kanatzidis, M. G. Semiconducting Tin and Lead Iodide Perovskites with Organic Cations: Phase Transitions, High Mobilities, and near-Infrared Photoluminescent Properties. Inorg. Chem. 2013, 52 (15), 9019-9038.

(9) Stein, F.; Palm, M.; Sauthoff, G. Structure and Stability of Laves Phases. Part I. Critical Assessment of Factors Controlling Laves Phase Stability. Intermetallics 2004, 12 (7-9), 713-720.

(10) Patrick, L. Inequivalent Sites and Multiple Donor and Acceptor Levels in SiC Polytypes. Phys. Rev. 1962, 127 (6), 1878-1880.

(11) Kamminga, M. E.; Fang, H.-H.; Filip, M. R.; Giustino, F.; Baas, J.; Blake, G. R.; Loi, M. A.; Palstra, T. T. M. Confinement Effects in Low-Dimensional Lead Iodide Perovskite Hybrids. Chem. Mater. 2016, 28 (13), 4554-4562.

(12) Tian, J.; Cordes, D. B.; Quarti, C.; Beljonne, D.; Slawin, A. M. Z.; Zysman-Colman, E.; Morrison, F. D. Stable 6H Organic-Inorganic Hybrid Lead Perovskite and Competitive Formation of $6 \mathrm{H}$ and 3C Perovskite Structure with Mixed A Cations. ACS Appl. Energy Mater. 2019, 2 (8), 5427-5437. 
(13) Stoumpos, C. C.; Mao, L.; Malliakas, C. D.; Kanatzidis, M. G. Structure-Band Gap Relationships in Hexagonal Polytypes and Low-Dimensional Structures of Hybrid Tin Iodide Perovskites. Inorg. Chem. 2017, 56 (1), 56-73.

(14) Nakamura, Y.; Shibayama, N.; Hori, A.; Matsushita, T.; Segawa, H.; Kondo, T. Crystal Systems and Lattice Parameters of $\mathrm{CH} 3 \mathrm{NH} 3 \mathrm{~Pb}(\mathrm{I} 1-\mathrm{XBrx}) 3$ Determined Using Single Crystals: Validity of Vegard's Law. Inorg. Chem. 2020, 59 (10), 6709-6716.

(15) Chen, D.; Li, J.; Chen, X.; Chen, J.; Zhong, J. Grinding Synthesis of APbX 3 (A = MA, FA, Cs; $\mathrm{X}=\mathrm{Cl}, \mathrm{Br}$, I) Perovskite Nanocrystals. ACS Appl. Mater. Interfaces 2019, 11 (10), $10059-10067$.

(16) Gratia, P.; Zimmermann, I.; Schouwink, P.; Yum, J.-H.; Audinot, J.-N.; Sivula, K.; Wirtz, T.; Nazeeruddin, M. K. The Many Faces of Mixed Ion Perovskites: Unraveling and Understanding the Crystallization Process. ACS Energy Lett. 2017, 2 (12), 2686-2693.

(17) Jeon, N. J.; Noh, J. H.; Yang, W. S.; Kim, Y. C.; Ryu, S.; Seo, J.; Seok, S. Il. Compositional Engineering of Perovskite Materials for High-Performance Solar Cells. Nature 2015, 517 (7535), 476-480.

(18) Azam, M.; Yue, S.; Xu, R.; Liu, K.; Ren, K.; Sun, Y.; Liu, J.; Wang, Z.; Qu, S.; Lei, Y.; et al. Highly Efficient Solar Cells Based on $\mathrm{Cl}$ Incorporated Tri-Cation Perovskite Materials. J. Mater. Chem. A 2018, 6 (28), 13725-13734.

(19) Noh, J. H.; Im, S. H.; Heo, J. H.; Mandal, T. N.; Seok, S. Il. Chemical Management for Colorful, Efficient, and Stable Inorganic-Organic Hybrid Nanostructured Solar Cells. Nano Lett. 2013, 13 (4), 1764-1769.

(20) Yang, W. S.; Park, B.-W.; Jung, E. H.; Jeon, N. J.; Kim, Y. C.; Lee, D. U.; Shin, S. S.; Seo, J.; Kim, E. K.; Noh, J. H.; et al. Iodide Management in Formamidinium-Lead-Halide Based Perovskite Layers for Efficient Solar Cells. Science (80-. ). 2017, 356 (6345), 1376-1379.

(21) Philippe, B.; Park, B. W.; Lindblad, R.; Oscarsson, J.; Ahmadi, S.; Johansson, E. M. J.; Rensmo, H. Chemical and Electronic Structure Characterization of Lead Halide Perovskites and Stability Behavior under Different Exposures-A Photoelectron Spectroscopy Investigation. Chem. Mater. 2015, 27 (5), 1720-1731. 
(22) Ito, S. Research Update: Overview of Progress about Efficiency and Stability on Perovskite Solar Cells. APL Mater. 2016, 4 (9), 091504.

(23) Wang, Y.; Wu, T.; Barbaud, J.; Kong, W.; Cui, D.; Chen, H.; Yang, X.; Han, L. Stabilizing Heterostructures of Soft Perovskite Semiconductors. Science 2019, 365 (6454), 687-691.

(24) Xu, W.; Hu, Q.; Bai, S.; Bao, C.; Miao, Y.; Yuan, Z.; Borzda, T.; Barker, A. J.; Tyukalova, E.; Hu, Z.; et al. Rational Molecular Passivation for High-Performance Perovskite LightEmitting Diodes. Nat. Photonics 2019, 13 (6), 418-424.

(25) Abdi-Jalebi, M.; Andaji-Garmaroudi, Z.; Cacovich, S.; Stavrakas, C.; Philippe, B.; Richter, J. M.; Alsari, M.; Booker, E. P.; Hutter, E. M.; Pearson, A. J.; et al. Maximizing and Stabilizing Luminescence from Halide Perovskites with Potassium Passivation. Nature 2018, 555 (7697), 497-501.

(26) Zheng, X.; Hou, Y.; Bao, C.; Yin, J.; Yuan, F.; Huang, Z.; Song, K.; Liu, J.; Troughton, J.; Gasparini, N.; et al. Managing Grains and Interfaces via Ligand Anchoring Enables 22.3\%Efficiency Inverted Perovskite Solar Cells. Nat. Energy 2020, 5 (2), 131-140.

(27) Pering, S. R.; Deng, W.; Troughton, J. R.; Kubiak, P. S.; Ghosh, D.; Niemann, R. G.; Brivio, F.; Jeffrey, F. E.; Walker, A. B.; Islam, M. S.; et al. Azetidinium Lead Iodide for Perovskite Solar Cells. J. Mater. Chem. A 2017, 5 (39), 20658-20665.

(28) Jodlowski, A. D.; Roldán-Carmona, C.; Grancini, G.; Salado, M.; Ralaiarisoa, M.; Ahmad, S.; Koch, N.; Camacho, L.; de Miguel, G.; Nazeeruddin, M. K. Large Guanidinium Cation Mixed with Methylammonium in Lead Iodide Perovskites for 19\% Efficient Solar Cells. Nat. Energy 2017, 2 (12), 972-979.

(29) Panetta, R.; Righini, G.; Colapietro, M.; Barba, L.; Tedeschi, D.; Polimeni, A.; Ciccioli, A.; Latini, A. Azetidinium Lead Iodide: Synthesis, Structural and Physico-Chemical Characterization. J. Mater. Chem. A 2018, 6 (21), 10135-10148.

(30) Wang, W.; Su, J.; Zhang, L.; Lei, Y.; Wang, D.; Lu, D.; Bai, Y. Growth of Mixed-Halide Perovskite Single Crystals. CrystEngComm 2018, 20 (12), 1635-1643.

(31) Jesper Jacobsson, T.; Correa-Baena, J. P.; Pazoki, M.; Saliba, M.; Schenk, K.; Grätzel, M.; Hagfeldt, A. Exploration of the Compositional Space for Mixed Lead Halogen Perovskites 
for High Efficiency Solar Cells. Energy Environ. Sci. 2016, 9 (5), 1706-1724.

(32) Levchuk, I.; Osvet, A.; Tang, X.; Brandl, M.; Perea, J. D.; Hoegl, F.; Matt, G. J.; Hock, R.; Batentschuk, M.; Brabec, C. J. Brightly Luminescent and Color-Tunable Formamidinium Lead Halide Perovskite FAPbX 3 (X = Cl, Br, I) Colloidal Nanocrystals. Nano Lett. 2017, $17(5), 2765-2770$.

(33) A. C. Larson and R.B. V. Dreele. Los Alamos National Laboratory Report LAUR; 2004.

(34) Holder, C. F.; Schaak, R. E. Tutorial on Powder X-Ray Diffraction for Characterizing Nanoscale Materials. ACS Nano 2019, 13 (7), 7359-7365.

(35) Tian, J.;Zysman-Colman, E.;Morrison, F. D. Size Isn't Everything - Compositional Variation in Hybrid Organic-Inorganic Lead Halide Perovskites: Kinetically- versus Thermodynamically-Controlled Synthesis. ChemRxiv. Prepr. 2021.

(36) Shannon, R. D. Revised Effective Ionic Radii and Systematic Studies of Interatomic Distances in Halides and Chalcogenides. Acta Crystallogr. Sect. A 1976, 32 (5), 751-767.

(37) Kumawat, N. K.; Dey, A.; Kumar, A.; Gopinathan, S. P.; Narasimhan, K. L.; Kabra, D. Band Gap Tuning of $\mathrm{CH} 3 \mathrm{NH} 3 \mathrm{~Pb}(\mathrm{Br} 1-\mathrm{XClx}) 3$ Hybrid Perovskite for Blue Electroluminescence. ACS Appl. Mater. Interfaces 2015, 7 (24), 13119-13124.

(38) Park, B.; Philippe, B.; Jain, S. M.; Zhang, X.; Edvinsson, T.; Rensmo, H.; Zietz, B.; Boschloo, G. Chemical Engineering of Methylammonium Lead Iodide/Bromide Perovskites: Tuning of Opto-Electronic Properties and Photovoltaic Performance. J. Mater. Chem. A 2015, 3 (43), 21760-21771.

(39) Wang, L.; Yuan, G. D.; Duan, R. F.; Huang, F.; Wei, T. B.; Liu, Z. Q.; Wang, J. X.; Li, J. M. Tunable Bandgap in Hybrid Perovskite $\mathrm{CH} 3 \mathrm{NH} 3 \mathrm{~Pb}(\mathrm{Br} 3-\mathrm{YXy})$ Single Crystals and Photodetector Applications. AIP Adv. 2016, 6 (4).

(40) Lee, S.; Levi, R. D.; Qu, W.; Lee, S. C.; Randall, C. A. Band-Gap Nonlinearity in Perovskite Structured Solid Solutions. J. Appl. Phys. 2010, 107 (2), 1-6.

(41) Chatterjee, S.; Payne, J.; Irvine, J. T. S.; Pal, A. J. Bandgap Bowing in a Zero-Dimensional Hybrid Halide Perovskite Derivative: Spin-Orbit Coupling: Versus Lattice Strain. J. Mater. 
Chem. A 2020, 8 (8), 4416-4427.

(42) Goyal, A.; McKechnie, S.; Pashov, D.; Tumas, W.; Schilfgaarde, M. Van; Stevanović, V. Origin of Pronounced Nonlinear Band Gap Behavior in Lead-Tin Hybrid Perovskite Alloys. Chem. Mater. 2018, 30 (11), 3920-3928.

(43) Hu, Z.; Lin, Z.; Su, J.; Zhang, J.; Chang, J.; Hao, Y. A Review on Energy Band-Gap Engineering for Perovskite Photovoltaics. Sol. RRL 2019, 3 (12), 1-9.

(44) Lehmann, F.; Franz, A.; Többens, D. M.; Levcenco, S.; Unold, T.; Taubert, A.; Schorr, S. The Phase Diagram of a Mixed Halide (Br, I) Hybrid Perovskite Obtained by Synchrotron X-Ray Diffraction. RSC Adv. 2019, 9 (20), 11151-11159. 

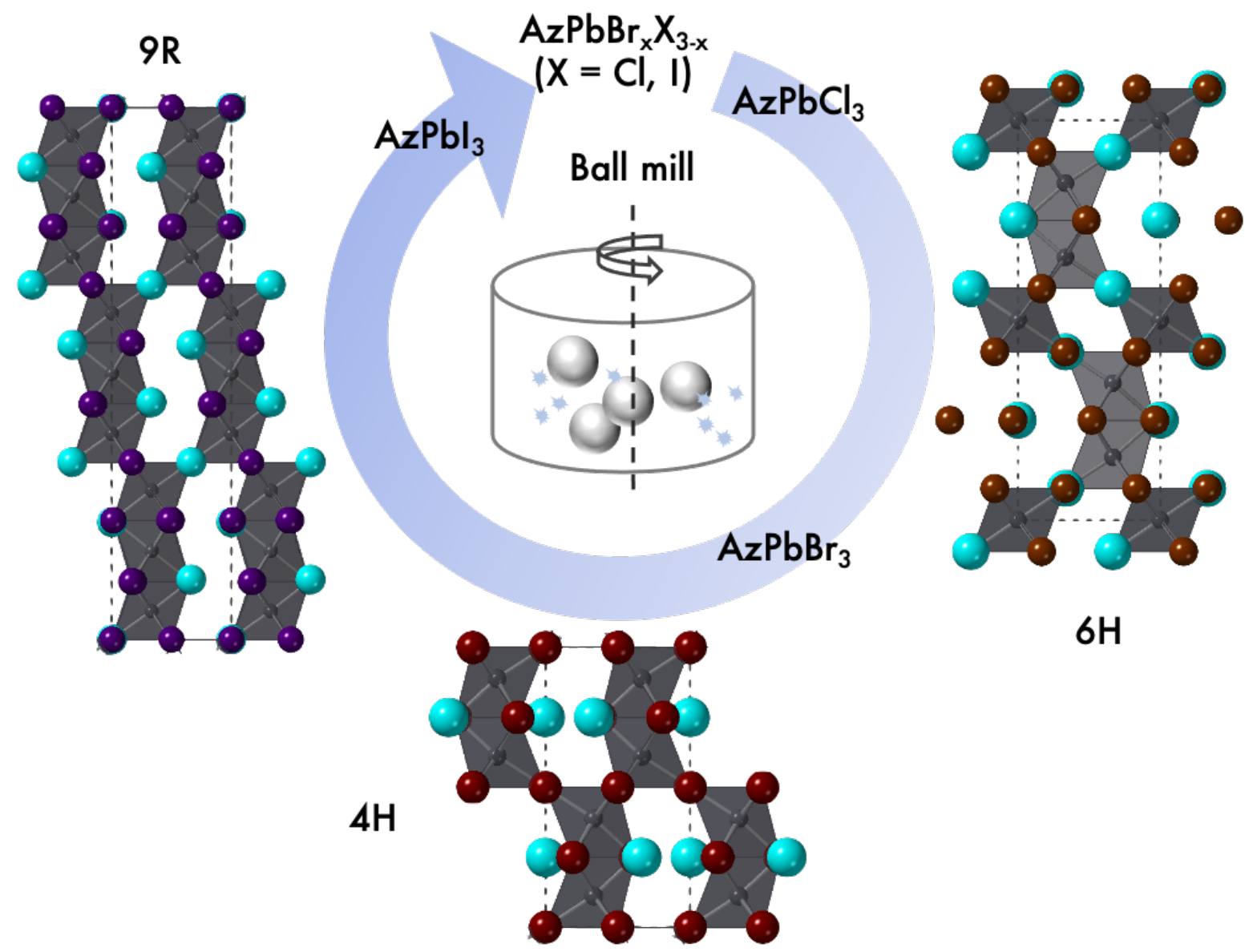